\title{
A 12-Month Study of the Efficacy of Rivastigmine in Patients with Advanced Moderate Alzheimer's Disease
}

\author{
Yahya Karaman $^{a}$ Füsun Erdoğan ${ }^{a}$ Emel Köseoğlu ${ }^{a}$ Tayfun Turan ${ }^{b}$ \\ Ali Özdemir Ersoy ${ }^{a}$ \\ Departments of a Neurology and ${ }^{b}$ Psychiatry, Medical Faculty, Erciyes University, Kayseri, Turkey
}

\section{Key Words}

Advanced moderate Alzheimer's disease $\cdot$ Rivastigmine

\begin{abstract}
The efficacy of a centrally active cholinesterase inhibitor, rivastigmine tartrate (ENA 713), in patients with advanced moderate Alzheimer's disease (AD) was evaluated in a 12-month placebo-controlled study. We aimed to investigate whether there was any evidence for the benefits of rivastigmine in patients with severe disease. These patients were compared with matched controls. In this study, 24 patients with advanced moderate $A D$ received rivastigmine for 12 months. Another 20 patients received placebo. Mean daily doses of rivastigmine in the higher-dose group at 3, 6, 9, and 12 months were $6.1 \pm 1.0,8.3 \pm 1.2,8.9 \pm 1.3$, and $10.7 \pm 1.6 \mathrm{mg} /$ day, respectively. Cognitive abilities were assessed using the 11-item cognitive subscale of the Alzheimer Disease Assessment Scale (ADAS-cog). Forty-five percent of placebo-treated patients declined by at least 4 points on the ADAS-cog. Conversely, only $18.3 \%$ of patients treated with rivastigmine declined by 4 or more points. Functional disabilities, as assessed using the Disability Assessment for Dementia Scale, remained significantly superi-
\end{abstract}

\section{KARGER}

Fax +41613061234

E-Mail karger@karger.ch

www.karger.com

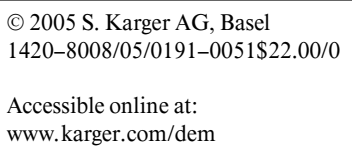

or in rivastigmine-treated patients compared with placebo-treated patients. Patients benefited from high-dose rivastigmine treatment on all outcome measures, including the Mini-Mental State Examination, Progressive Deterioration Scale, as well as the Global Deterioration Scale. Patients receiving rivastigmine for 12 months significantly improved compared with placebo-treated patients $(p<0.001)$. By 52 weeks, patients originally treated with 6-12 mg/day rivastigmine had a significantly better cognitive function than patients originally treated with placebo. Long-term rivastigmine treatment appeared to be well tolerated in patients with advanced moderate $A D$ and significantly benefits the cognitive and functional symptoms of AD.

Copyright @ 2005 S. Karger AG, Basel

\section{Introduction}

Alzheimer's disease (AD) is the most common type of dementia encountered in older patients. While its etiology is still unknown, the pathological manifestations of AD seen at autopsy are unmistakable: the characteristic amyloid plaques and neurofibrillary tangles $[1,2]$. It is also recognized that cholinergic pathways in the cerebral cor- 
tex and basal forebrain are compromised in patients with $\mathrm{AD}$, and the cholinergic deficiency that results may contribute to the cognitive deficits observed in these patients [3-5]. Pharmacological enhancement of the surviving cholinergic system may therefore provide efficacious symptomatic treatment of $\mathrm{AD}$ [6-8].

To date, the most successful pharmacological approach to the treatment of $\mathrm{AD}$ has been with cholinesterase inhibitors (ChEIs), which are felt to increase acetylcholine $(\mathrm{ACh})$ levels in the central nervous system by interfering with the hydrolysis of ACh by acetylcholinesterase (AChE) and/or butyrylcholinesterase $[9,10]$.

ChEIs act by inhibiting the degradation of ACh. The clinical efficacy of these drugs has been characterized by cognitive, functional, and global improvements in patients with $\mathrm{AD}$, and there is evidence that they may delay the progression of dementia.

Various ChEIs have been approved by the US Food and Drug Administration to treat AD: tacrine, donepezil, rivastigmine, and galantamine $[3,11]$. Clinical use of tacrine has been limited by the high rate of side effects and need of serial blood monitoring for hepatotoxicity [12]. More recently, clinical trials of donepezil [13-15], rivastigmine [16-19] and galantamine $[9,20]$ have demonstrated benefits on cognitive and global measures. The randomized controlled trials supporting these claims have involved patients with mild to moderately severe $\mathrm{AD}$ [Mini-Mental State Examination (MMSE) score of 5-26, or stages 3-6 on the Global Deterioration Scale (GDS)], but unfortunately, there is little information about the effects of these agents on advanced $\mathrm{AD}$, especially regarding the long-term effects.

Rivastigmine is a pseudo-irreversible ChEI [2, 3, 9, 21]. It inhibits both $\mathrm{AChE}$ and butyrylcholinesterase at standard dosage and has shown greater selectivity for brain tissue in preclinical trials, particularly for the cortex and hippocampus $[17,22]$. There are strong theoretical reasons to believe that agents inhibiting both of these enzymes will have greater clinical efficacy than that of other AChE selective agents [18, 22-24]. Since it is not associated with hepatotoxicity or elevated liver enzyme levels, there is no requirement for liver function monitoring with rivastigmine therapy $[23,25,26]$. The use of rivastigmine in other dementing disorders, such as Lewy body dementia and vascular dementia has been studied $[19,27,28]$.

Because of the paucity of information regarding the effects of rivastigmine on advanced $\mathrm{AD}$, especially on the long-term effects, we aimed to study long-term effects of rivastigmine treatment and to determine whether rivas- tigmine may delay the progression of cognitive impairment in advanced moderate AD. We evaluated the efficacy of rivastigmine for a period of 12 months in patients with advanced moderate AD.

\section{Methods}

This was a randomized, placebo-controlled, 12-month study undertaken at the Neurology Clinic, Erciyes University Hospital, Kayseri, Turkey. The study included male and female subjects between 60 and 90 years of age. Patients were included in the study if they met each of the following criteria: having a history of cognitive decline that was gradual in onset and progressive over a period of at least 6 months; meeting criteria for Alzheimer's type dementia as described in the DSM-IV [29]; diagnosis of probable AD according to the criteria of the National Institute of Neurological and Communicative Disorders and Stroke and AD and Related Disorders Association [30], and an MMSE [31] score of 14 and a score of 30 on the 11-item cognitive subscale of the Alzheimer Disease Assessment Scale (ADAS-cog) [32], specially for advanced moderate AD. In all cases, the presence of $\mathrm{AD}$ was supported by evidence from computed tomographic or magnetic resonance imaging studies performed during the 6 months prior to entry.

All patients were either fully ambulatory or able to walk with an assistive device and had vision and hearing sufficient for compliance with testing procedures. Female patients were either at least 5 years postmenopausal or had been surgically sterilized prior to entry.

Patients who had been treated for AD with a cholinomimetic agent in the preceding 60 days were also excluded. Any other antidementia medication (estrogen, selegiline, nonsteroidal anti-inflammatory drug) had to be discontinued before entry to the study. Any other drugs with anticholinergic or cholinomimetic effects were avoided. The use of drugs for concomitant conditions was permitted during the study, with the exception of sedative-hypnotics and sedating cough, which were discontinued, if possible $72 \mathrm{~h}$ before cognitive testing.

Patients with evidence of other psychiatric or neurological disorders and those who had clinically significant or active gastrointestinal, renal, hepatic, endocrine or cardiovascular diseases were excluded from entering trial. None of the patients had a history of alcohol or drug abuse, and none were known to be hypersensitive to ChEIs.

Patients had a responsible caregiver, who, together with the patient (or an appropriate representative) provided written informed consent to participate in the study.

The study was conducted according to the Declaration of Helsinki and subsequent revisions, and was approved by the Ethics Committee of the Erciyes University Hospital, Kayseri, Turkey.

Patients were randomly assigned to receive treatment with rivastigmine or placebo. Rivastigmine and placebo were administered as identical tablets taken twice daily. In the rivastigmine group, patients received rivastigmine twice daily with food. The dose of rivastigmine was escalated every 2 weeks in increments of $1.5 \mathrm{mg}$ twice a day. The maximum possible dose was $12 \mathrm{mg}$ /day rivastigmine.

At the conclusion of the 8-week study visit, participants who tolerated the drug well and perceived benefit were invited to continue rivastigmine treatment. Those continuing treatment were followed at 3-month intervals with clinical assessments, routine laboratory mon- 
itoring (standard laboratory tests, ECG), ADAS-cog, MMSE, and the Clinician's Interview-Based Impression of Change plus Caregiver Input (CIBIC-plus) [33].

Outcome measures for the study included the ADAS-cog, and MMSE; functional ability was assessed using the Disability Assessment for Dementia Scale (DAD) [34] and the AD Cooperative Study/ Activities of Daily Living Inventory (ADCD/ADL) [35]. On the other hand, the Progressive Deterioration Scale (PDS) [36] and GDS [37] were assessed and the values at the beginning of the treatment were compared with the result after 52 weeks.

Results are expressed as mean \pm standard deviation. Comparisons between groups were performed by means of one-way analysis of variance (ANOVA). The threshold for determining statistical significance was $p<0.05$. If ANOVA was significant, a Scheffé post hoc test was applied to determine between which pairs of groups the difference was.

Changes in ADAS-cog and DAD scores were compared between the treatment groups by means of ANOVA. Possible effects of baseline characteristics on efficacy findings were tested using ANOVA for ADAS-cog, CIBIC-plus, MMSE, PDS, and GDS. Rates on ADAS$\operatorname{cog}$ (changes of baseline scores) were also calculated and compared by means of Fisher's exact test.

All randomized patients who received trial medication were included in the analyses of baseline characteristics. For our post hoc analysis of advanced moderate AD patients, the primary statistical analysis was performed on the intention to treat population, using observed case data, as was done in the individual trials.

\section{Results}

In this study, 24 patients with moderate advanced AD received rivastigmine for 12 months, while another 20 patients received placebo for the same period. Patient demographic characteristics did not differ between treatment groups. The baseline characteristics of these two groups are shown in table 1.

To establish whether the small differences between rivastigmine and placebo baseline scores in MMSE and ADAS-cog have any effect on the outcome results, baseline scores were included as a covariate in an ANOVA of efficacy; all ANOVA tests confirmed no significant effects on cognitive outcomes $(\mathrm{p}>0.1)$.

The mean doses of rivastigmine at $3,6,9$, and 12 months were $6.1 \pm 1.0,8.3 \pm 1.2,8.9 \pm 1.3$, and $10.7 \pm$ $1.6 \mathrm{mg} /$ day, respectively. Twenty-one patients tolerated the drug well and reached a dose of 6-12 mg/day at 12 months. Three patients were not able to tolerate the escalating doses of rivastigmine to optimal levels owing to the incidence of gastrointestinal side effects. These patients were maintained on a lower dose of rivastigmine (3-6 mg/ day); mean daily doses of rivastigmine in the higher-dose group at 3, 6, 9, and 12 months were 6-12. mg/day. Adverse events by treatment groups are shown in table 2 .
Table 1. Baseline characteristics of the rivastigmine and the placebo group

\begin{tabular}{lcc}
\hline Characteristics & $\begin{array}{l}\text { Placebo } \\
(\mathrm{n}=20)\end{array}$ & $\begin{array}{l}\text { Rivastigmine } \\
(\mathrm{n}=24)\end{array}$ \\
\hline Men/women & $9 / 11$ & $11 / 13$ \\
Age, years & $73.40 \pm 0.90$ & $74.11 \pm 0.87$ \\
AD duration, years & $2.0 \pm 0.1$ & $1.9 \pm 0.1$ \\
Weight, kg & $69.45 \pm 0.40$ & $67.70 \pm 0.32$ \\
Total MMSE score & $13.20 \pm 0.21$ & $11.40 \pm 0.20$ \\
ADAS-cog score & $39.30 \pm 0.57$ & $41.65 \pm 1.41$ \\
Total DAD score & $51.75 \pm 1.90$ & $53.60 \pm 2.40$ \\
ADCS/ADL score & $56.30 \pm 0.90$ & $55.20 \pm 0.85$ \\
CIBIC-plus & $4.42 \pm 0.08$ & $4.40 \pm 0.07$ \\
GDS & $4.90 \pm 0.2$ & $5.1 \pm 0.3$ \\
\hline
\end{tabular}

Values are means \pm SEM.

Table 2. Number of patients with adverse events

\begin{tabular}{lcc}
\hline Event & $\begin{array}{l}\text { Placebo } \\
(\mathrm{n}=20)\end{array}$ & $\begin{array}{l}\text { Rivastigmine } \\
(\mathrm{n}=24)\end{array}$ \\
\hline Nausea & 15.0 & 16.6 \\
Vomiting & 10.0 & 12.5 \\
Dizziness & 15.0 & 8.3 \\
Anorexia & 10.0 & 8.3 \\
Headache & 0 & $8.3^{*}$ \\
Abdominal pain & 5.0 & 4.1 \\
\hline
\end{tabular}

$*$ p $<0.05$ vs. placebo.

Treatment with high-dose (6-12 $\mathrm{mg} /$ day) rivastigmine was not associated with any increase in risk for mortality, significant adverse events, effects on laboratory parameters, ECG, or cardiovascular vital signs. No consistent or clinically significant drug-related laboratory abnormalities were found with regard to vital signs, ECGs, or laboratory values including hepatic enzymes.

The results of the observed case analysis for primary outcome measures at 52 weeks are provided in table 3 .

On the ADAS-cog, patients receiving placebo steadily deteriorated with a mean change from baseline of 4.5 points. The scores of patients in the rivastigmine group improved compared with their baseline values. The mean changes from baseline scores for patients receiving rivastigmine compared with placebo were statistically significant. A significantly higher percentage of treated AD 
Table 3. Primary outcome measure results after 52 weeks (observed case analysis)

\begin{tabular}{lrrr}
\hline Outcome measures & \multicolumn{1}{c}{$\begin{array}{c}\text { Placebo } \\
(\mathrm{n}=20)\end{array}$} & $\begin{array}{l}\text { Rivastigmine } \\
(\mathrm{n}=21)\end{array}$ & $\mathrm{p}$ value \\
\hline ADAS-cog & $-4.45 \pm 0.8$ & $0.82 \pm 0.71$ & $<0.001$ \\
CIBIC-plus & $0.51 \pm 0.2$ & $0.16 \pm 0.14$ & $<0.001$ \\
MMSE & $1.2 \pm 0.1$ & $0.20 \pm 0.1$ & $<0.010$ \\
PDS & $-5.44 \pm 0.3$ & $-1.14 \pm 1.1$ & $<0.001$ \\
ADCD/ADL & $-0.15 \pm 0.1$ & $-0.33 \pm 0.2$ & $<0.012$ \\
DAD & $-3.40 \pm 0.2$ & $0.12 \pm 0.2$ & $<0.001$ \\
GDS & $-0.34 \pm 0.1$ & $-0.10 \pm 0.2$ & $<0.001$ \\
\hline
\end{tabular}

patients demonstrated a clinically meaningful improvement on the ADAS-cog scores as defined by a 4-point or greater change from baseline. More patients receiving rivastigmine treatment as compared with those receiving placebo showed a clinically meaningful improvement. Forty-five percent of placebo-treated patients declined by at least 4 points on the ADAS-cog. Conversely, only $18.3 \%$ of patients treated with rivastigmine declined by 4 or more points.

On the CIBIC-plus test, subjects receiving placebo deteriorated from their baseline scores, while the rating of patients receiving rivastigmine showed either no deterioration or significantly less deterioration than that of patients receiving placebo in all evaluation points $(\mathrm{p}<$ $0.001)$.

On activities of daily living as measured by the PDS, patients receiving placebo progressively declined, with a mean deterioration from baseline of more than 5 points at week 52. PDS scores of rivastigmine-treated subjects remained steadily near baseline (1.4 points). The difference in scores between the rivastigmine group and the placebo group was 4 points $(\mathrm{p}<0.001)$.

On the GDS, patients in the high-dose rivastigmine group showed significantly less deterioration than those in the placebo group at week $52(\mathrm{p}<0.001)$.

On the MMSE, the rivastigmine-treated patients scored significantly better than those receiving placebo. Patients receiving placebo deteriorated by 1.2 points from baseline on the MMSE, while those receiving rivastigmine improved by 0.20 points from baseline.

By the end of 12 months, ADAS-cog scores and MMSE scores were significantly improved with rivastigmine over placebo $(p<0.001)$ for cognitive functions. On the MMSE, DAD, CIBIC-plus, GDS, and ADCD/ADL, scores in the rivastigmine group were significantly differ- ent from those in the placebo group for global assessment of change, activity of daily living and disease severity $(\mathrm{p}<$ 0.001 ).

\section{Discussion}

The objective of this paper was to analyze the longterm outcome of rivastigmine treatment and to determine the efficacy of rivastigmine in patients with advanced moderate AD. The limitation of this trial was that the number of the subjects included was small.

Advanced moderate AD patients were those with baseline MMSE scores $\leq 14$ and ADAC-cog scores of approximately $\geq 130$ points [38]. This 52 -week trial confirms that rivastigmine is efficacious in the treatment of advanced moderate AD. Patients treated with rivastigmine demonstrated improvements in cognitive functions and in the global clinical function compared to placebo. There is evidence of a dose-response effect, with the patients treated with rivastigmine $6-12 \mathrm{mg} /$ day showing greater improvement than the patients treated with rivastigmine $3-6 \mathrm{mg} /$ day. Three patients were maintained on a lower dose of rivastigmine (3-6 $\mathrm{mg}$ /day) and did not show any difference from baseline on the MMSE and ADAS-cog. Since 3 patients were treated with a lower dose of rivastigmine, no statistical comparison was performed on the patients treated with high-dose rivastigmine.

Also in various other studies [23-39], patients treated with the lower dose and the higher dose of rivastigmine had significantly better cognitive functions than the placebo group.

Although there was no difference between the patient and control groups regarding the ADAS-cog, MMSE, DAD, CIBIC-plus, GDS, and ADCD/ADL scores at the beginning of the study, at the end of the study, it was shown that the patients treated with rivastigmine exhibited meaningful differences when compared with the placebo group.

In the literature, there are limited studies about longterm effects of rivastigmine therapy on advanced AD. The long-term efficacy of rivastigmine was evaluated in a 26-week extension phase of a 26-week, placebo-controlled study. At week 26, placebo-treated patients who entered the extension phase had a decline on the ADAS-cog of 3.8 points. After 1 year, the difference between the rivastigmine group (6-12 mg/day) and the placebo group showed an initial improvement; i.e., the difference between the scores of the rivastigmine group and the placebo group after 52 weeks was 4.2 points [18]. A subanalysis of the 
patients with moderately severe AD, at week 52 , showed that patients who had initially been treated with rivastigmine (6-12 $\mathrm{mg} /$ day) had a decline from baseline in the mean ADAS-cog score of 1 point, whereas patients originally randomized to the placebo group had a significantly greater decline of 5.5 points [40].

In various studies, patients treated with high-dose rivastigmine exhibited a clinically meaningful improvement compared with patients treated with placebo [24, $25,40-44]$.

There were no obvious overall trends of clinically relevant differences between the treatment groups in vital signs (mean systolic and diastolic blood pressure, heart rate, body temperature), mean body weight, physical and neurologic examination, hematological or biochemical analysis, electrocardiographic measurement, and urine analysis during the study. The adverse events associated with rivastigmine in this study were generally those expected from cholinergic stimulation, and similar to those reported with other ChEIs [25, 39]. The adverse events were generally not severe and occurred most frequently during the dose escalation phase and may be reduced further by using a slower dose escalation [23].

Rivastigmine was well tolerated, adverse events occurring at least $6 \%$ more often in the rivastigmine group than the placebo group. More than 55\% of patients in both treatment groups (rivastigmine and placebo) reported at least one adverse event during the trial (table 2). The incidence of adverse events during the dose escalation phase of the study in the rivastigmine group was greater than that of the placebo group. During the maintenance phase, the difference between the placebo and rivastigmine groups in the frequency of adverse events was reduced. The most common adverse events were nausea (16.6\%), vomiting $(12.5 \%)$, dizziness $(8.3 \%)$, anorexia $(8.3 \%)$, headache $(8.3 \%)$, and abdominal pain $(4.1 \%)$.

We observed less side effects than reported in the literature. In patients with $\mathrm{AD}$ compared with the control group, the most important side effect was headache.

We had more favorable results than the studies in the literature which examined the effects of rivastigmine during 52 weeks. We recommend the use of high-dose rivastigmine for patients with advanced moderated AD. There is no study about taking AchEI for more than 1 year, but patients can use AchEI for a longer period if there is no side effect and as long as the patient has clinical benefits from it.

We conclude that patients with $\mathrm{AD}$ may continue to experience efficacy benefits of clinical value from maintained, long-term rivastigmine treatment, even in the more advanced phases of the disease. Rivastigmine also appears to be well-tolerated in patients with advanced moderate $\mathrm{AD}$.

\section{References}

1 Blass JP: Pathophysiology of Alzheimer's syndrome. Neurology 1993;43(suppl 4):S25-S38.

2 Gauthier S: Clinical Diagnosis and Management of Alzheimer's Disease. London, Martin Duniz Ltd, 1999, pp 57-67, 249-269.

3 Davis KL, Haroutunian V: Strategies for the treatment of Alzheimer's disease. Neurology 1993;43(suppl 4):S52-S55.

$\checkmark 4$ Engelborghs S, Deyn PP: The neurochemistry of Alzheimer's disease. Acta Neurol Belg 1997; 97:67-84

$\checkmark 5$ Selkoe DJ: The molecular pathology of Alzheimer's disease. Neuron 1991;6:487-498.

$\checkmark 6$ Sands LP, Katz I, Schneider L: Assessing individual patients for cognitive benefits from acetylcholinesterase inhibitors. Alzheimer Dis Assoc Disord 1999;13:26-34.

7 Sarter M, Bruno JP: Cognitive functions of cortical acetylcholine. Brain Res Brain Res Rev 1997;23:28-46.

8 Sirvio J: Strategies that support declining cholinergic neurotransmission in Alzheimer's disease patients. Gerontology 1999;45(suppl 1):314.

Efficacy of Rivastigmine in Patients with

Advanced Moderate AD
9 Hogan DB, Patterson C: Treatment of Alzheimer's disease and other dementias - Review and comparison of the cholinesterase inhibitors. Can J Neurol Sci 2002;29:306-314.

10 Taylor P: Development of acetylcholinesterase inhibitors in the therapy of Alzheimer's disease. Neurology 1998;51(suppl 1):S30-S35.

11 Knopman D, Morris JC: An update on primary therapies for Alzheimer's disease. Arch Neurol 1997;54:1406-1409.

12 Maltby N, Broe GA, Creasey H, Jorm AF, Christensen H, Brooks WS: Efficacy of tacrine and lecithin in mild to moderate Alzheimer's disease: Double blind trial. BMJ 1994;308: 879-883.

13 Cummings JL, Vinters HV, Cole GM, et al: Alzheimer's disease. Etiologies, pathophysiology, cognitive reserve, and treatment opportunities. Neurology 1998;51(suppl 1):S2-S17.

14 Doody RS, Stevens JC, Beck C, et al: Practice parameter: Management of dementia (an evidence-based review). Report of the Quality Standards Subcommittee of the American Academy of Neurology. Neurology 2001;56: 1154-1166.
Weinstock M: Selectivity of cholinesterase inhibition. Clinical implications for the treatment of Alzheimer's disease. CNS Drugs 1999; 12:307-323.

16 Anand R, Messina J, Hartman R: Dose response effect of rivastigmine in the treatment of Alzheimer's disease. Int J Geriatr Psychopharmacol 2002;2:68-72.

17 Cutler ND, Polinsky RJ, Sramek JJ, et al: Dose-dependent CSF acetylcholinesterase inhibition by SDZ ENA 713 in Alzheimer's disease. Acta Neurol Scand 1998;97:244-250.

18 Farlow M, Anand R, Messina JA, Hartman R, Veach J: A 52-week study of the efficacy of rivastigmine in patients with mild to moderately severe Alzheimer's disease. Eur Neurol 2001; 46:110.

19 Spencer CM, Noble S; Rivastigmine. Drug

Aging 1998; 13:391-411.
Ballard CG: Advances in the treatment of Alzheimer's disease: Benefits of dual cholinesterase inhibition. Eur Neurol 2002;47:64-70.

21 Roe CM, Anderson MJ, Spivack B: Use of anticholinergic medication by older adults with dementia. J Am Geriatr Soc 2002;50:836-842. 
22 Giacobini E, Spiegel R, Enz A: Inhibition of acetyl- and butyryl-cholinesterase in the cerebrospinal fluid of patients with Alzheimer's disease by rivastigmine: Correlation with cognitive benefit. J Neural Transm 2002;109: 1053-1065.

23 Corey-Bloom J, Anand R, Veach J: ENA 713 B352 Study Group. A randomized trial evaluating the efficacy and safety of ENA 713 (rivastigmine tartrate): A new acetylcholinesterase inhibitor, in patients with mild to moderately severe Alzheimer's disease. Int J Geriatr Psychopharmacol 1998;1:55-65.

-24 Darreh-Shori T, Almkvist O, Guan ZZ, et al: Sustained cholinesterase inhibition in AD patients receiving rivastigmine for 12 months. Neurology 2002;59:563-572.

-25 Rosler M, Anand R, Cicin-Sain A: Efficacy and safety of rivastigmine in patients with Alzheimer's disease: International randomised controlled trial. BMJ 1999;318:633-638.

-26 Williams BR, Nazarians A, Gill MA: A review of rivastigmine: A reversible cholinesterase inhibitor. Clin Ther 2003;25:1634-1653.

27 McKeith I, DelSer T, Emre M, et al: Efficacy of rivastigmine in dementia with Lewy bodies: A randomised, double-blind, placebo-controlled international study. Lancet 2000;356:20312036.

28 Moretti R, Torre P, Antonello RM, et al: Rivastigmine in subcortical vascular dementia: A comparison trial on efficacy and tolerability for 12 months follow-up. Eur J Neurol 2001;361363.

29 American Psychiatric Association: Diagnostic and Statistical Manual of Mental Disorders, ed 4. Washington, American Psychiatric Association, 1994.
30 Mc Khann G, DrachmanD, Folstein M, Katzman R, Price D, et al: Clinical diagnosis of Alzheimer's disease: Report of the NINCDSADRDA Work Group under the auspices of Department of Health and Human Services Task Force on Alzheimer's Disease. Neurology 1984;34:939-944.

31 Folstein MF, Hug PR, Folstein SE: Mini-mental state. A practical method for grading the cognitive state of patients for the clinician. J Psychiatr Res 1975; 12:189-192.

32 Rosen WG, Mohs RC, Davis KL: A new rating scala for assessing demented patients. Am J Psychiatry 1984;141:1356-1364.

33 Schneider LS, Olin JT, Doody RS: Validity and reliability of the Alzheimer's Disease Cooperative Study-Clinical Global Impression of Change. Alzheimer Dis Assoc Disord 1997;11: 22-32.

34 Gelinas I, Gauthier L, Mclntryne M, Gauthier S: Development of a functional measure for persons with Alzheimer's disease: The disability assessment for dementia. Am J Occup Ther 1999;53:471-481.

35 Galasko D, Bennett D, Sano M, et al: An inventory to assess activities of daily living for clinical trials in Alzheimer's disease. The Alzheimer's Disease Cooperative Study. Alzheimer Dis Assoc Disord 1997;11:33-39.

36 Dejong R, Osterland OW, Roy GW: Measurement of quality of life changes in patients with Alzheimer's disease. Clin Ther 1989;11:545554.

37 Reisberg B, Ferris SH, de Leon MJ, et al: Global deterioration scale (GDS). Psychopharmacol Bull 1988;24:661-663.
38 Feldman H, Sauter A, Donald A, Gelinas I Gauthier S, et al: The Disability Assessment for Dementia Scale: A 12-month study of functional ability in mild to moderate severity Alzheimer's disease. Alzheimer Dis Assoc Disord 2001;15:89-95.

39 Grossberg GT, Stahelin HB, Messina JC, Anand R: Lack of adverse pharmacodynamic drug interactions with rivastigmine and 22 classes of medication. Int $\mathrm{J}$ Geriatr Psychiatry 2000;15:242-247.

40 Doraiswamy M, Hartman R, Graham S: Early intervention with a cholinesterase inhibitor produces long-term beneficial effects in moderately severe $\mathrm{AD}$ patients. Neurobiol Aging 2000;21:275.

41 Farlow MR, Hake A, Messina J, Hartman R, Veach J, Anand R: Response of patients with Alzheimer disease to rivastigmine treatment is predicted by the rate of disease progression. Arch Neurol 2001;58:417-422.

42 Potki SG, Anand R, Hartman R, Veach J, Grossberg G: Impact of Alzheimer's disease and rivastigmine treatment on activities of daily living over the course of mild to moderately severe disease. Prog Neuropsychopharmacol Biol Psychiatry 2002;26:713-720.

43 Desai A, Grossberg G: Review of rivastigmine and its clinical applications in Alzheimer's disease and related disorders. Eur Neurol 2000; 44:236-241.

44 Forette F, Anand R, Gharabowi G: A phase II study in patients with Alzheimer's disease to assess the preliminary efficacy and maximum tolerated dose of rivastigmine. Eur J Neurol 1999;6:423-429.

\section{Erratum}

Collerton D, Burn D, McKeith I, O’Brien J: Systematic review and meta-analysis show that dementia with Lewy bodies is a visual-perceptual and attentional-executive dementia. Dement Geriatr Cogn Disord 2003;16:229-237.

In the above cited article there was an error in table 1 . The 9 th row should read:

Table 1. Description of task characteristics

\begin{tabular}{|c|c|c|c|c|c|c|c|}
\hline \multirow[t]{2}{*}{ Characteristic } & \multirow[t]{2}{*}{ Task requirement } & \multirow[t]{2}{*}{ Exemplars } & \multirow{2}{*}{$\begin{array}{l}\% \text { agreement } \\
\text { between } \\
\text { raters }\end{array}$} & \multicolumn{4}{|c|}{ Contribution to factors, $\%$ variance accounted for } \\
\hline & & & & $\begin{array}{l}\text { general verbal/ } \\
\text { non-verbal } \\
30\end{array}$ & $\begin{array}{l}\text { attentional } \\
\text { executive } \\
17\end{array}$ & $\begin{array}{l}\text { visual } \\
\text { perceptual } \\
14\end{array}$ & $\begin{array}{l}\text { verbal } \\
\text { memory } \\
9\end{array}$ \\
\hline Executive & $\begin{array}{l}\text { requires the manipulation } \\
\text { of rules }\end{array}$ & Wisconsin card sorting & 92 & 0.17 & 0.85 & & \\
\hline
\end{tabular}

